\title{
Violencia y Estado. La posición de Hegel acerca del estado de naturaleza ${ }^{1}$
}

\section{Violence and State. Hegel's position on the state of nature}

\author{
Juan Ignacio Arias Krause ${ }^{2}$ \\ Patricio Landaeta Mardones ${ }^{3}$ \\ Centro de Estudios Avanzados, Universidad de Playa \\ Ancha (Chile)
}

Recibido: 16-09-14

Aprobado: 09-10-14

\section{Resumen}

La dualidad entre "estado de naturaleza" y "Estado civil", propuesta por los teóricos modernos del derecho natural, es asumida por G. W. F. Hegel sometiéndola a una crítica radical que deriva en su singular comprensión de política y derecho. Según el filósofo, ambos "estados" se encuentran operando

\footnotetext{
${ }^{1}$ Este artículo es parte del Proyecto de Postdoctorado FONDECYT N 3150334: "Aportes para una teoría de la soberanía latinoamericana", realizado por el investigador responsable Juan Ignacio Arias Krause en el Centro de Estudios Avanzados de la Universidad de Playa Ancha, Chile bajo el patrocinio de Patricio Landaeta Mardones.

2 (juanignacioak@gmail.com) Doctor en Filosofía por la Pontificia Universidad Católica de Valparaíso, Chile. Máster en Filosofía de la Historia: Democracia y Orden Mundial. Investigador Postdoctoral en Centro de Estudios Avanzados, Universidad de Playa Ancha

Publicaciones recientes: Landaeta, Patricio; Arias, Juan Ignacio (ACEPTADO). "El quiebre ético de la comunidad ética: la sociedad civil", Revista Universum, Universidad de Talca (SCOPUS).

Landaeta, Patricio; Arias, Juan Ignacio (2013), "La interpretación política de la tragedia griega de Hegel”, Revista Co-herencia, Vol. 10, N 19. Universidad EAFIT. (Publicado ISI)

Arias, Juan Ignacio (2013), "La crítica del Derecho natural moderno en la filosofía de Hegel". Universitas. Revista de Filosofía, Derecho y Política. N ${ }^{\circ} 18$. Universidad Carlos III. ISSN 16987950. España (Publicado Latindex)

${ }^{3}$ (patricio.landaeta@upla.cl). Doctor en Filosofía por la Pontificia Universidad Católica de Valparaíso y por la Université Paris VIII Vincennes-Saint-Denis, Francia; Máster en Estudios Avanzados en Filosofía y Doctor Europeo en Filosofía por la Universidad Complutense de Madrid, España. Publicaciones recientes: Espinoza, R., Alvarado, B., Landaeta, P. (2014), "Música y sensación sonora: John Tavener" en, Hispania Sacra. (Publicado ISI)

Landaeta, P., y Espinoza, R. (2014), "Geofilosofía de la ciudad para pensar más allá del organismo" en, Aurora. Revista de filosofia, Pontificia Universidad Católica de Sao Paulo. Publicado ISI.
} 
activamente en distintos niveles de la realidad política sin constituir más que en apariencia una dualidad dicotómica. Lo que se propone mostrar es que [1] la violencia que caracteriza tradicionalmente al estado de naturaleza es un momento fundacional de la política; [2] la crítica a la presentación de un estado de naturaleza sustantivizado, para [3] concluir con la interiorización que hace Hegel de aquellos elementos que habían sido expuestos como exteriores, y que cumplen una función fundamental en el desarrollo del Estado.

Palabras-clave: Hegel, Estado de naturaleza, Estado civil, Política, Derecho, Violencia.

\begin{abstract}
The dual comprehension between the idea of "state of nature" and of "civil State" proposed by the modern theorist of natural right is assumed by G. W. F. Hegel in a critical manner that derives in his particular understanding of politic and of right. According to him, both states work together in different levels of reality. What we are trying to show is [1] that the violence that traditionally characterizes the sate of nature is the foundational moment of politics; [2] Hegel's critique to the presentation of a substantivized state of nature, in order to conclude [3] with the process of interiorization carried out by Hegel of those elements that previously appear as external, that accomplish a fundamental role in the development of the State.
\end{abstract}

Key-words: Hegel, State of nature, Civil State, Politic, Right, Violence.

\title{
Introducción
}

El carácter racional que tiene el derecho natural en la modernidad le impone la exigencia y el deber de comprender el derecho a partir de un principio adecuado, entendiendo por tal un principio que contenga validez no para tal o cual contingencia ("El hombre vale porque es hombre y no porque sea judío, católico, protestante, alemán o italiano"4), ni que se pretenda legítimo por un principio externo (ya sea por una legitimidad basada en una parcialidad racial, cultural o divina), sino que en sí mismo contenga una validez universal y sirva como fundamento para todos los hombres. ${ }^{5}$. El derecho natural se acoge por

\footnotetext{
${ }^{4}$ G. W. F. Hegel, Principios de la filosofia del derecho, Buenos Aires, Sudamericana, 2004, p. 198.

${ }^{5}$ Misma validez exigida por Descartes para la fundamentación de la ciencia en sus Meditaciones metafísicas (libro escrito doce años después que de Hugo Grocio, De iure belli ac pacis, de 1625, texto éste que es considerado el que da inicio a la modernidad en el derecho): "Me era preciso intentar seriamente, una vez en mi vida, deshacerme de todas las opiniones que hasta entonces 
ello al fundamento de la razón, en cuanto ésta ya no es considerada como una hermana menor de la fe, sino que en absoluta independencia asume el deber de convertirse en la rectora del orden social y de contener aquella violencia que surgiera tras la crisis religiosa que marcó el final de la Edad Media y el comienzo de la Moderna, la cual desvelara, a su vez, el conflicto de la soberanía tanto en las relaciones entre las naciones como internas a ellas. Las leyes del derecho, por tanto, dejan de ser una participación de las leyes eternas ${ }^{6}$, debiendo ser deducidas a partir de un método científico. La naturaleza humana ya no es, para el jurista moderno, una participación divina, de modo que debe dejar de confiar en la recta ratio de la conducta humana, para realizar una exposición racional de su naturaleza, desde donde se puedan demostrar las normas racionales de su conducta, y asumir dentro de ella los elementos conflictivos que surgen a partir de esta nueva estructura normativa?.

El problema que se presenta con tal forma de proceder es que a partir de esta concepción se deberá encontrar un fundamento tal en el hombre que opere como su esencia, y desde la cual se legitime su actividad práctica, con lo cual la acción de la razón se vuelve de amplio espectro: llamada a establecer el orden sobre los distintos campos donde el hombre se desarrolla, también tiene el deber de someter a su dominio aquellos elementos que no se ajustan espontáneamente a él e inclusive muchas veces le son adversos, tal como se presentan esos dominios en el llamado estado de naturaleza, estado que bajo el imperio de la razón deberá ser sometido como aquello otro que surge de la realización del estado racional, que es el Estado civil ${ }^{8}$.

Sin embargo, tal estado de cosas perdería tal rigidez una vez que las exigencias que imponía este tipo de razón señalaran su crisis, tras el derrumbe

había creído y empezar enteramente de nuevo desde los fundamentos si quería establecer algo firme y constante en las ciencias." Rene Descartes, Meditaciones Metafisicas, Santiago de Chile, Universitaria, 1974, p. 13.

${ }^{6}$ La definición tomista es elocuente: "Ley Natural no es otra cosa que la participación, en la creatura racional, de la Ley Eterna." (Tomás de Aquino, S.Th.I.II.q.91) La ley natural, por tanto, tiene su legitimidad no en ella misma, sino en cuanto está vinculada con el lado racional que comprende la misma idea de ley y, más específicamente, en cuanto participa de la ley eterna.

7 "Proponiendo la reducción de la ciencia del derecho a ciencia demostrativa los iusnaturalistas sostienen, por primera vez con tanto ímpetu en la secular historia de la jurisprudencia, que la tarea del jurista no es la de interpretar reglas ya dadas, que como tales no pueden dejar de resentir las condiciones históricas en las que fueron emitidas, sino aquella mucho más notable de descubrir las reglas universales de la conducta por medio del estudio de la naturaleza del hombre, de igual manera que el científico de la naturaleza que finalmente ha dejado de leer a Aristóteles y se ha puesto a escudriñar el cielo." Norberto Bobbio y Michelangelo Bovero, Sociedad y Estado en la filosofia política moderna. El modelo iusnaturalista y el modelo hegeliano-marxiano, México, Fondo de Cultura Económica, 1986, pp. 29-30.

${ }^{8}$ El estado de naturaleza no describe un momento histórico sino un modelo teórico de explicación de la vida social previa o posterior a la existencia del Estado. Según Charles-Yves Zarka, comentador de Hobbes, este estado correspondería al de la "guerra civil" y estaría caracterizado por una disposición anímica al deseo infinito de poder y por el "derecho natural" de cada uno sobre todas las cosas, comprendiendo en ese todo incluso los propios hombres. (Cf. Yves Charles Zarka, Hobbes y el pensamiento político moderno, Barcelona, Herder, 1997, p. 140) 
de aquella racionalidad, llevada hasta el extremo por la Ilustración y puesta en tela de juicio a partir de los movimientos intelectuales alemanes de pasados la mitad del siglo XVIII, y resquebrajada por completo por el Romanticismo y el Idealismo alemán, cuestión que habría acontecido - siguiendo la tesis del jurista italiano, Norberto Bobbio- de manera radical en la Filosofía del derecho de G. W. F Hegel ${ }^{9}$. En efecto, situado en este problema, Hegel se enfrentará a la postura de una naturaleza entendida como un estado originario, el que se encuentra escindido de la realización histórica y social del hombre, haciendo frente, de este modo, a las posturas contractualistas modernas, que postulaban tal estado como una realidad previa al estado civil, el cual sirve (aunque sea metodológicamente) a la realización de éste. Tal manera de asumir el problema conduce a efectuar una crítica a cada uno de los enfrentamientos y las escisiones que, a su vez, se derivan de él, como son, por ejemplo, las que se dan entre la violencia y el orden, entre la comunidad natural y la comunidad política, el miedo y la seguridad, la racionalidad y los afectos, entre otros conflictos que son propios a este enfrentamiento. Tales serán los problemas que serán tratados a continuación, revisando con más detalles las posturas que asume Hegel para acabar con esta idea del estado de naturaleza.

\section{La violencia originaria: la fuerza como fuente de orden}

Inscrito dentro de la tradición del derecho natural moderno, Hegel antepone al comienzo del Estado civil un momento de desorden, de desequilibrio y de violencia entre los particulares, los cuales luchan o bien se ven sometidos en función de sus intereses y pasiones. La unidad congregante de semejante relación se pierde en puntos disgregados, donde no podría existir ningún tipo de orden estable, pues siempre se encontraría supeditada a aquella lucha que imposibilitaría el establecimiento de un principio unificador. Es por ello que, lejos de ajustarse a la teoría contractual ${ }^{10}$, la cual presenta el comienzo de la comunidad política a través del pacto entre particulares en vistas a una

9 "La Filosofía del Derecho de Hegel a la vez que se presenta como la negación de todos los sistemas de derecho natural, también es el último y más perfecto sistema de derecho natural, el cual, en cuanto último, representa el final y en cuanto más perfecto, representa el cumplimiento de aquello que lo había precedido." Norberto Bobbio, Hegel y el iusnaturalismo [Diánoia, vol. 13, núm. 13, 1967], p. 55.

10 Hegel es un abierto detractor de la teoría contractualista, a la cual antepone la voluntad universal a la voluntad de los particulares, aquella es anterior a ésta y la constituye intrínsecamente. En sus Lecciones sobre la historia de la filosofia señala sobre la voluntad general presentada por Rousseau: "la tergiversación acerca de la voluntad general comienza desde el momento en que el concepto de libertad no debe ser interpretado en el sentido de la arbitrariedad fortuita de cada cual, sino en el sentido de la voluntad racional en y para sí [...] La voluntad general debe ser [...] la voluntad racional, aunque no tenga la conciencia de ello; el Estado no es, tampoco, por tanto, una de las asociaciones concertadas por la arbitrariedad de los individuos." G. W. F. Hegel, Lecciones sobre la historia de la filosofia, Tomo III, México, Fondo de Cultura Económica, 2005, p. 400. 
convivencia que les otorgue paz y seguridad ${ }^{11}$, Hegel retoma la cultura griega para situar al comienzo del estado político un momento de violencia que sin estar ajustado a derecho, lo instituye:

La violencia [Gewalt] que hay en el fondo de este fenómeno [el de la lucha por el reconocimiento] no es por ello fundamento del derecho, aunque sea momento necesario y justificado del tránsito [Übergange] desde el estado de la autoconciencia [que se encuentra] abismada en el deseo y singularidad al estado de la autoconciencia universal. Es el comienzo fenoménico o exterior de los estados, no su principio sustancial ${ }^{12}$.

Este pasaje se encuentra situado -tal como apunta su traductor, el filósofo español Ramón Valls Plana- en el momento histórico de los héroes fundadores del mundo clásico, los cuales tenían el derecho excepcional otorgado por la divinidad de ejercer la fuerza para instituir la comunidad política ${ }^{13}$. Sin embargo, como señala Valls Plana, tal fuerza no es el mero acto irracional de violentar al otro en vistas a intereses particulares, sino que es una violencia que si bien la realizan unos hombres sobre otros, no contiene el sentido peyorativo que suele tener este tipo de acción. En efecto, la palabra alemana que utiliza Hegel es Gewalt, la cual si bien se puede traducir por violencia, se usa "también para nombrar los «poderes del estado» englobando, claro está, la fuerza coercitiva de estos poderes"14 15 .

11 "Y, por consiguiente, mientras persiste ese derecho natural de cada uno con respecto a todas las cosas, no puede haber seguridad para nadie (por fuerte o sabio que sea) de existir durante todo el tiempo que ordinariamente la Naturaleza permite vivir a los hombres. De aquí resulta un precepto o regla general de la razón, en virtud de la cual, cada hombre debe esforzarse por la paz, mientras tiene la esperanza de lograrla; y cuando no puede obtenerla, debe buscar y utilizar todas las ayudas y ventajas de la guerra. La primera fase de esta regla contiene la ley primera y fundamental de naturaleza, a saber: buscar la paz y seguirla. La segunda, la suma del derecho de naturaleza, es decir: defendernos a nosotros mismos, por todos los medios posibles." Thomas Hobbes, Leviatán, O la materia, forma y poder de una república eclesiástica y civil, México, Fondo de Cultura Económica, 2006, p. 107.

${ }^{12}$ G. W. F. Hegel, Enciclopedia de las ciencias filosóficas, Madrid, Alianza Editorial, 2008, p. 479.

13 El héroe fundador del mundo griego tenía la virtud de poder hacer aparecer de manera abrupta aquella hybris violenta al momento de actuar en su calidad de fundador: "Quien desee crear y fundar un lugar nuevo tiene que estar lleno de soberbia. También necesita mostrar la audacia y hacer alarde de la violencia del que se arranca de un espacio familiar." (Marcel Detienne, Apolo con el cuchillo en la mano, Madrid, Akal, 2001, p. 137). Pero éste, como figura visible perdía sus atributos al quedar la ciudad fundada. La forma legal que significa el orden instituido lo excluía y en su lugar pasaba a formar parte del culto público. A su muerte era enterrado al centro de la ciudad, como presencia de aquella violencia originaria, una presencia inquietante y elevada a forma divina, a la cual se le ofrecían permanentes sacrificios. "Mientras está vivo, el «oikista» rinde culto a Apolo Arquegeta, el dios que preside su empresa. Una vez muerto es el fundador el que recibe un culto oficial y, presumiblemente, también de arquegeta [...] el «oikista» difunto es colocado en el ágora, en el espacio público abierto a las asambleas y reservado a las construcciones oficiales mezcladas con los santuarios de los dioses." (Ibid., p. 123). En este sentido, destaca también lo rescatado por San Agustín de Cicerón a propósito de Rómulo al cual cita: "«A Rómulo, que fundó esta ciudad, le hemos colocado entre los dioses inmortales con el amor y con la fama»" (San Agustín, La Ciudad de Dios, XV, 5)

${ }^{14}$ G. W. F. Hegel, Enciclopedia de las ciencias filosóficas, Op. cit., p. 479.

15 Jacques Derrida en su trabajo "Fuerza de ley" realiza la misma distinción. Ahí señala: "la 
En este contexto, y con fin a profundizar en el momento histórico al que hace referencia Hegel y al carácter violento que supone el momento de la fundación de ciudades en la época de la colonización griega, podemos nombrar concretamente al constructor de casas, como el ilustre Basileus, Nausitoo, padre de Alcínoo ${ }^{16}$. Este "oikista" es él mismo arkhekhete, fundador. De modo que la pólis, de la mano del fundador, aparecerá como un nuevo arkhé de la comunidad ocupando el lugar del oîkos. Este arkhé instituirá la propia pluralidad que se manifiesta en la sagrada repartición original del territorio de la ciudad ${ }^{17}$. Dentro de las primeras labores de la fundación, el fundador enciende la llama del Hogar común (Hestia koiné), delimita un terreno para vivir, asty, divide las zonas y las separa: vivienda, publico, sagrado; y se comparte entre los colonizadores el territorio para el cultivo, $k h o ̂ r a^{I 8}$. Esta división sagrada se convierte en la primera ley de la ciudad en la que, sin embargo, continúa viva la imagen del oîkos: la ciudad comienza con la palabra del oikista que divide la ciudad como también había sido dividida la casa: desde el centro continuando con los espacios de mayor importancia ${ }^{19}$.

De esta manera, la fundación de la polis funciona siguiendo un modelo similar al del sacrificio: en el sacrificio se coge la ofrenda, se hunde el cuchillo, se riega la sangre y se reparte el sagrado alimento entre los comensales. En la fundación, por su parte, el oikistes divide la tierra virgen: lo indeterminado se determina, la tierra se convierte en territorio. Así como la carne deviene alimento tras su cocción, la tierra deviene territorio gracias a la acción del fundador. Siguiendo los pasos del sacrificio la fundación de ciudades procede de la siguiente manera: el cuchillo es reemplazado por la operación de cálculo del geómetra concentrado en dividir la ciudad de acuerdo a la armonía cósmica, acto seguido, el geónomo la reparte echándola a la suerte ${ }^{20}$. Sólo entonces la tierra que es pura disposición -como la víctima del sacrificio- se colma con la obra del fundador que ordena el territorio según la perfección del $\operatorname{cosmos}^{21}$. De

palabra «Gewalt». Tanto en francés como en inglés se traduce a menudo como «violencia» [...] estas traducciones, sin ser completamente injustas, esto es, completamente violentas, son interpretaciones muy activas que no hacen justicia al hecho de que Gewalt también significa para los alemanes poder legítimo, autoridad, fuerza pública. Gesetzgebende Gewalt es el poder legislativo, geistliche Gewalt, el poder espiritual de la Iglesia, Staatsgewalt, es la autoridad o el poder del Estado.Gewalt es a la vez, por tanto, la violencia y el poder legítimo, la autoridad justificada." Jacques Derrida, Fuerza de ley. El «fundamento místico de la autoridad», Madrid, Tecnos, 2008, p. 17.

${ }^{16}$ Cf. Marcel Detienne, Op. Cit., p. 118.

${ }^{17}$ La fundación es sagrada tanto por contar con el beneplácito de Apolo como por el encendido del nuevo fuego que acoge a los homoios con la llama de Hestia, viva desde la ciudad que vio partir para siempre a un grupo de sus ciudadanos: es forzoso que el fundador antes de dirigirse al lugar propuesto por el oráculo, tome parte del fuego de Hestia.

${ }^{18}$ Cf. Homero, Odisea, VI, 4-10.

${ }^{19}$ Cf. Marcel Detienne, Op. Cit., p. 120.

${ }^{20}$ Cf. Ibid., p. 122.

${ }^{21}$ Como señala Detienne: "Megara Hyblea, una de las primeras colonias, fundada alrededor del 730. En su planta el espacio público está bien diferenciado de los reservados para habitación y comercio. Con sus lotes repartidos, es ciudad modelo históricamente habitada." Ibíd., p. 120. 
tal manera, los gestos del fundador proponen un modelo político: el fundador toma posesión de la tierra, la convierte en territorio e inmediatamente la divide y reparte entre los ciudadanos en partes iguales (dasmos). Al igual como funcionará la asamblea, la repartición del lote, khlero, es inseparable de la fundación de una ciudad ${ }^{22}$.

Con este acto de violencia ritual, lo que hace el mundo griego es establecer la comunidad política y, con ello, el imperio de la paz interior, quedando la violencia (la violencia extranjera, bárbara) en los márgenes de la polis, pues una vez erigida las murallas de ésta, la violencia es expulsada por el orden interno, quedándose en las afueras de la ciudad y por ello en las afueras de la política. La fundación de la ciudad inaugura el derecho: el orden del territorio constituye la primera ley, por ello el significado del territorio para los griegos es fundamental, no sólo para las póleis democráticas que se afianzan como unidades territoriales en comunicación y asociación, sino también para el mundo antiguo que concebía la medida del cosmos en la perfecta unión de cielo y tierra ${ }^{23}$.

Sin embargo, como apunta Hegel en la cita arriba puesta, tal comienzo es tan sólo el "comienzo fenoménico" de los estados, distinguiéndolo de su principio sustancial. Tal acto fundacional supone la instauración de un nuevo orden ahí donde, o no existía ninguno, o bien se le superpone a otro ya existente ${ }^{24}$. En cualquiera de ambos casos la acción conlleva un acto de violencia, de corte radical con lo establecido y de imposición de una legalidad nueva $^{25}$. Ya sea del tipo que sea el modo de justificar tal acción (ansias de expansión, intereses económicos, principios religiosos) necesariamente la

\footnotetext{
${ }^{22}$ Cf. Ibid., p. 122.

23 Igualmente se conoce de la existencia de ciudades arcaicas no fundadas. Cf. Louis Gernet, Droitet institutions en Grèce Antique, Paris, Flamarion, 2000, p. 266.

${ }^{24}$ Tal es la función que cumplen, en opinión de Hegel, esos individuos históricos que son los héroes. Éstos realizan la elevación de un momento a otro del espíritu, a través de su propia particularidad, paso que conlleva la "disolución, destrucción de la realidad precedente" (Lecciones sobre la filosofía de la historia universal, Madrid, Alianza editorial, 1989, p. 91). Es a través de esta elevación "donde surgen las grandes colisiones entre los deberes, las leyes, los derechos existentes, reconocidos, y ciertas posibilidades que son opuestas a este sistema, lo menoscaban e incluso destruyen sus bases y realidad." Ídem.

${ }^{25}$ Tal concepción de la fundación del imperio de la ley, por medio de la violencia (Gewalt) también es destacado por Derrida en la segunda parte del texto mencionado en la nota 15 , donde señala la diferencia de la actividad de la violencia en su relación con el derecho y la justicia entre las culturas griegas y la judía: "Hay a continuación la distinción entre la violencia fundadora del derecho, a la que se le llama «mítica» (hay que sobreentender «griega», me parece), y la violencia destructiva del derecho (Rechtsverninchtend), a la que se le llama divina (hay que sobreentender «judía», me parece)." Jacques Derrida, Op. Cit., p. 82.

Tal cita hace mención al texto en el que se encuentra inspirado el de Derrida, como es el de Walter Benjamin Hacía la crítica de la violencia, donde el autor sostiene: "Si la violencia mítica instaura derecho, la violencia divina lo aniquila; si aquélla pone límites, ésta destruye ilimitadamente; si la violencia mítica inculpa y expía al mismo tiempo, la divina redime; si aquélla amenaza, ésta golpea; si aquélla es letal de manera sangrienta, ésta viene a serlo de forma incruenta." Walter Benjamin, Hacía la crítica de la violencia [en Walter Benjamin: Obras, libro II, vol. 1, Madrid, Abada], p. 202.
} 
fundación debe encontrarse apoyada de un procedimiento que le proporcione una validez soberana al acto fundacional. Ya sea, como en el caso griego, una expansión colonial regida por un origen mítico, o bien como en el mundo romano, el que se encontraba respaldado por el derecho, ambos suponen un poder ajeno y la violencia con la que actúan no responden al orden interno que pretenden implantar. Claro ejemplo de ello es la pax romana, la cual aseguraba la paz en los pueblos que formaban parte del imperio, los mismos que habían sido dominados en muchos casos por la fuerza y gracias a ella se garantizaba esa $\mathrm{paz}^{26}$. A partir de esta contradicción que caracteriza la fundación de la comunidad política es de donde surge el problema de su origen, pues éste conlleva el replanteamiento de la validez del acto fundacional y la violencia que supone, y el hecho de considerarla (a la violencia, en tanto Gewalt) como algo externa a la política o bien como algo que le es inmanente ${ }^{27}$. El problema que se encuentra a la base de esto pone en cuestión aquello que sea propiamente lo político ${ }^{28}$.

La teoría política que se inicia con la hipótesis de un estado de naturaleza previo al civil"29, nos interesa por su ruptura con el momento de "violencia e

26 "Puede que las dinámicas provinciales pasasen por distintos estadios en su proceso de integración en el imperio romano, desde una oposición y resistencia manifiesta a ser pacificada para finalmente terminar integrada. Por ejemplo, la idea de la provincia pacatissima quiere reforzar la idea de que la paz en esta zona ha sido alcanzada recientemente y, por lo tanto, puede que en un tiempo anterior no lo estuviese. Para pasar después a un nuevo orden en el que la provincia llegue a ser fiel y pacífica (Pacem fidelitatemque populi Syracusani), obviamente la acción del ejército estaba siempre justificada. [...] En cualquier caso la paz en las provincias es un mecanismo para asegurarse el uso de sus recursos humanos y naturales (tributos, relaciones comerciales, etc.) para el bien de la república romana, como queda de manifiesto especialmente en In Verrem actio prima que tiene su acción ubicada en Sicilia. De ahí que justifique siempre la acción del ejército para asegurar el control de la provincia." Francisco Muñoz, La Pax Romana, Granada, Editorial Universidad de Granada, Campus Universitario de Cartuja, 1998, p, 222.

${ }^{27}$ Como se destacará más adelante, el acto fundacional contiene en sí mismo la validez jurídica del acto, cuestión que es destacada también por Derrida en el ya citado texto: "Dado que en definitiva el origen de la autoridad, la fundación o el fundamento, la posición de la ley, sólo pueden, por definición, apoyarse en ellos mismos, éstos constituyen en sí mismos una violencia sin fundamento. Lo que no quiere decir que sean injustos en sí, en el sentido de «ilegales» o «ilegítimos». No son ni legales ni ilegales en su momento fundador, excediendo la oposición entre lo fundado y lo no fundado, entre todo fundacionalismo o antifundacionalismo." Jacques Derrida, Op. Cit., p. 34.

${ }^{28} \mathrm{La}$ investigación, por tanto, se dirige hacia una instancia previa a la fundación de la política, aquello que la posibilita y, sin embargo, no se agota con ella: eso es el acto fundacional -político- que es considerado como un acto ajeno a la política, pero fundadora de ella. Tal como lo plantea Chantal Mouffe: “Concibo 'lo político' como la dimensión de antagonismo que considero constitutivas de las sociedades humanas, mientras que entiendo 'la política' como el conjunto de las prácticas e instituciones a través de las cuales se crea un determinado orden, organizando la existencia humana en el contexto de la conflictividad derivada de lo político." Chantal Mouffe, En torno a lo político, Buenos Aires, Fondo de Cultura Económica, 2007, p. 16.

${ }^{29}$ Dado a que se han hecho numerosas referencias al texto de Derrida, posiblemente sea necesario (e inclusive justo, para no ejercer violencia sobre él) referirnos al texto mencionado anteriormente que lo inspira, como es el Hacia la crítica de la violencia de Walter Benjamin, en relación, claro está, al tema que nos ocupa. El tema del texto se encuentra dedicado, tal como su nombre lo señala, al tema de la violencia, y a la categorización de ésta en cuanto justa o injusta, cuestión que se alcanza en su relación con derecho (de hecho el texto da inicio con semejante relación: "La tarea de una crítica de 
injusticia" ${ }^{30}$, por aquella acción que los ha llevado a convertirse en fundadores de ciudades y, con ello, a la instauración de un Estado político, dirigido por una ley que se encuentra por encima del orden previo, natural.

Ahora bien, la violencia de la que se ha hablado cumple una función fundamental que surge de la necesidad previa al orden político, que en la teoría política moderna se ha caracterizado en la dualidad entre "estado de naturaleza" y "Estado civil". Sin embargo, con la presentación de tales momentos como una dualidad, lo que se hace es agudizar el problema, cubriéndolo artificialmente. La tesis de un estado de naturaleza originario y confinado a los límites de la historia política no sirve más que como hipótesis de trabajo teórico, pues en la práctica carece de validez ${ }^{31}$. No obstante, más allá de examinar la presencia de esta hipótesis de trabajo en los principales filósofos y pensadores políticos modernos, el análisis del estado de naturaleza nos parece de singular importancia, pues con su examen teórico se actualiza el problema político de la violencia como la presencia de aquel estado de naturaleza que se renueva de manera constante y en cada caso donde actúa un individuo, y éste al interior del estado político. Tal es la evidencia -explicita, por ejemplo, en Spinoza- de que el hombre no se encuentra determinado exclusivamente por la razón, sino también -y de manera radicalmente más fuerte- por los afectos, los cuales son la expresión concreta de aquel estado de naturaleza, el que la determina a partir del poder que cada uno de sus integrantes posee ${ }^{32}$. De este modo, se inserta

la violencia puede ser definida como la exposición de la relación de la violencia con el derecho y con la injusticia." (Walter Benjamin, Op. Cit., p.183)) Este problema, clásico dentro de la tradición del derecho moderno (sea dentro del ámbito del iusnaturalismo o el iuspositivismo), es tratado con suficiente originalidad por Benjamin, pues el análisis por él hecho rompe con la consideración de tratar la violencia como un medio para un fin que a posteriori se le pueda atribuir la categoría de justo o injusto, ajustado a derecho o no. Lo que hace el pensador alemán es desvincularse de la concepción de justicia determinada por la idea de fin, para analizar simple y puramente el medio. Mediante este análisis criticará la posición propia del derecho natural que acá se ha presentado: la de la violencia como instauradora de derecho y, a la vez, criticará la posición de la violencia como mantenedora de derecho, por no alcanzar legalidad en sí misma, sino sólo gracias al fin que pretende lograr a través de él.

${ }^{30}$ G. W. F. Hegel, Principios de la filosofia del derecho, Op. Cit., p. 307. El parágrafo al que se hace referencia se encuentra en los últimos momentos de la Filosofia del derecho, los que se encuentran dedicados a la Historia universal, como el momento último del espíritu objetivo dentro del sistema hegeliano. El parágrafo localiza dentro del despliegue del derecho la aparición y la función política específica de los héroes fundadores.

"Surgir en determinaciones legales e instituciones objetivas, que tienen su punto de partida en el matrimonio y en la agricultura, constituye el derecho absoluto de la idea, la forma de cuya realización puede aparecer como un favor y una legislación divinos o como violencia e injusticia. Este derecho es el derecho de los héroes para la fundación de estados." Ibid., p. 307.

${ }^{31}$ Tal es la tesis del propio Hobbes, quien reconoce la validez teórica del estado de naturaleza, pero no su existencia real. El filósofo inglés pone en tela de juicio tal estado de naturaleza (que para él es de guerra de todos contra todos), señalando: "Acaso puede pensarse que nunca existió un tiempo o condición en que se diera una guerra semejante, $\mathrm{y}$, en efecto, yo creo que nunca ocurrió generalmente así, en el mundo entero". Thomas Hobbes, Op. Cit., p. 103.

32 "Cuando dirigí mi atención a la política, no me propuse exponer algo nuevo e inaudito, sino 
dentro de la actividad humana el problema, haciendo del análisis antropológico la base del problema político. El problema del estado de naturaleza no se encuentra en las afueras de la política, ni siquiera como un momento político en sí mismo, sino que constituye al hombre en su actividad práctica.

Es en esta línea de interiorización de aquello que había sido puesto en las afueras de lo político, como Hegel -quien, como hemos visto en la cita puesta arriba, tiene presente la violencia como inicio de la comunidad-se distanciará de la idea de algo oculto en el origen de la política, y de la consideración del estado de naturaleza como un momento sustantivado, como una esencia inmóvil que instituye al hombre en sociedad, y de la que no puede escapar, pero sí recubrir racionalmente. Pero la distancia que toma no es por negar esa instancia pre-política, sino por distinguir distintos niveles estructurales de realidad, ya que tal estado no sería más que un momento de paso, llamado a ser superado. La posición asumida entorno al estado de naturaleza se puede rastrear en diversos momentos de su obra que iremos revisando, pero en este momento inicial nos parece importante destacar nuevamente el fragmento ya citado de la Enciclopedia donde establece la violencia como el comienzo del Estado, pero donde destaca que tal comienzo es meramente un "comienzo fenoménico o exterior de los estados, no su principio sustancial" 33 .

La diferencia entre comienzo fenoménico y principio sustancial, señalado por Hegel, indica que tal momento es necesario para el surgimiento del Estado como, a la vez, para la realización fenoménica del mismo, el que a cada instante va constatando nuevos comienzos, cada vez que ese momento de violencia se renueva ${ }^{34}$. Es esto, justamente, lo que le da validez a aquello que Hegel llama el

demostrar de forma segura e indubitable o deducir de la misma condición de la naturaleza humana sólo aquellas cosas que están perfectamente acordes con la práctica [...] me he esmerado en no ridiculizar ni lamentar ni detestar la acciones humanas, sino en entenderlas. Y por eso he contemplado los afectos humanos $[\ldots]$ no como vicios de la naturaleza humana, sino como propiedades que le pertenecen." Baruj Spinoza, Tratado político, Madrid, Alianza Editorial, 2004, p. 85.

Así pues, el comenzar desde la experiencia implica dejar a un lado la especulación filosófica tradicional sobre la política, que piensa en un hombre ideal para construir una sociedad ideal, para comenzar desde el hombre natural, del estado de naturaleza, para deducir a partir de él el estado político que le resulte conveniente y útil. Al caracterizarse ese hombre por la multitud de afectos, Spinoza no reniega de ellos para encausarlos a una idea de unidad, sino afirmándolos, comprende que es necesario mantener esa multitud: habría que buscar el mejor modo de mantenerlos controlados en vistas a la seguridad del Estado.

"Se trata-sostiene Antonio Negri- de concebir la relación entre el desarrollo de las cupiditates individuales y el constituirse de la multitudo: éste es el objeto de la política, el cual, en cambio, no es el objeto ni de la moral ni de la religión. Pero éste es a su vez el sujeto de la política" Antonio Negri, Spinoza subversivo, Madrid, Akal, 2000, p. 43.

${ }^{33}$ G. W. F. Hegel, Enciclopedia de las ciencias filosóficas, Op. Cit., p. 479.

${ }^{34}$ Nada hay en el fondo de lo político, nada que no haya emergido ya en la lucha por el reconocimiento: lo que lo posibilita y a partir de él crea las formas intersubjetivas, no es un fondo que se encuentre en las profundidades de la individualidad, sino una nada que lo arroja hacia fuera. La condición abismada de las autoconciencias caracteriza el momento negativo que se encuentra en el interior de éstas, que no otorga permanencia alguna como para asentar en ella algo así como su principio. De hecho el movimiento que se produce entre ese estado y el Estado político es transitivo 
principio sustancial del Estado, con lo cual indica el carácter inmanente que da vida y vivifica a cada momento el desarrollo estatal (cada una de sus mediación de las cuales se compone) y al cual éste se ordena, tal como es la libertad. Ciertamente en Hegel tal principio sustancial, que es la libertad, no puede desplegarse plenamente si no es a través de aquel dominio que comprende lo fenoménico $^{35}$, de ahí que se haga preciso incorporar estos elementos dentro de una teoría del derecho, no como algo otro que permanece en las afueras de lo político, sino que late en su interior, posibilitándolo.

Bajo esta perspectiva es como Hegel desarrollará una crítica radical a la idea del estado de naturaleza, tal como fue concebida por los pensadores iusnaturalistas modernos, no para rechazarla, sino para asumirla dentro de la teoría de la eticidad al interior de su Filosofía del derecho.

\section{Posición crítica frente al estado de naturaleza}

Mito o ficción fundacional de la teoría iusnaturalista moderna, el estado de naturaleza, tal como sostiene Rousseau, es un estado que "no existe, que quizás no haya existido, que probablemente no existirá jamás", pero que se reconoce como valido de presentar pues "es necesario tener justas nociones para juzgar acertadamente nuestro estado presente" "36. Semejante necesidad no puede estar en apariencia más lejana a la posición de Hegel, cuando éste asegura que "el estado de naturaleza no es un estado jurídico y el hombre debe, por tanto, sobreponerse a él" 37 . Cuestión que se reitera en la Enciclopedia, donde asegura que del estado de naturaleza "no se puede decir nada más verdadero que hay que salir de él"38. Sin embargo, es tan sólo en apariencia que ambas posturas se presentan como contradictorias,

(para señalar este paso, Hegel emplea el término técnico Übergange, propio del carácter transitivo de la lógica del ser), uno pasa al otro, y en ese paso se disipa su consistencia, se convierte en una pura nada que ha devenido otro.

${ }_{35}$ Numerosas son las referencias en las que Hegel incorpora los diversos elementos que corresponde al orden fenoménico dentro de su teoría del derecho, con lo cual se puede responder a la extendida crítica que lo sitúan como el pensador de un Estado meramente racional. Esto puede verse desde la propia definición que da de Estado, en la que incorpora como necesarios para el desarrollo de éste, los elementos particulares y contingentes de la sociedad:

"El estado es la realidad efectiva de la libertad concreta. Por su parte, la libertad concreta consiste en que la individualidad personal y sus intereses particulares tengan su total desarrollo y el reconocimiento de su derecho (en el sistema de la familia y de la sociedad civil)" G. W. F. Hegel, Principios de la filosofia del derecho, Op. Cit., p. 233.

Y un poco antes, había asegurado:

"El estado no es un producto artificial sino que se halla en el mundo, y está por lo tanto en la esfera del arbitrio, la contingencia y el error." Ibid., p. 232.

${ }^{36}$ J. J. Rousseau, Discurso sobre el origen de la desigualdad entre los hombres, México, Porrúa, 2004, p. 106.

${ }^{37}$ Hegel, Lecciones sobre la historia de la filosofia, Op. Cit., p. 334.

${ }^{38}$ Hegel, Enciclopedia de las ciencias filosóficas, Op. Cit., pp. 532-533. 
ya que con las palabras de Hegel se ratificaría lo dicho por Rousseau, pues la determinación propia del estado civil nace de la acción negativa ejercida sobre el estado que se le contrapone, de modo que para entender o establecer un juicio sobre una época presente, necesario se haría conocer aquel otro estado, que funcionaría como comienzo de éste, manteniéndose en tensión el estado de naturaleza y el Estado civil. Esta tensión posibilitaría la aparición de los elementos opuestos y separados por un límite, y donde cada uno tiene su determinación gracias al otro.

Sin embargo, el problema dentro de la esfera política es la persistencia que tiene el estado de naturaleza en rehuir de toda determinación. Cuando Hegel sostiene muy tempranamente, en la novena de las Tesis de habilitación para ser profesor en la Universidad de Jena, que "el estado de naturaleza no es injusto, es la razón por la que hay que salir de él" 39 , da cuenta exactamente de este hecho: no es injusto porque es previo a toda determinación legal, por lo tanto, la inocencia plena que caracterizaría al hombre en ese momento le impide acceder al ámbito de la justicia, de modo que no siendo injusto tampoco es justo. Cada una de estas determinaciones pertenecen al terreno ganado por la conciencia en su vínculo con la objetividad, por ello la referencia al estado de naturaleza sólo puede llevarse a cabo mediante una abstracción de todo contenido que no sea natural o, lo que vendría a ser lo mismo, propiamente histórico. Es por esta razón que lo único que se puede decir del habitante de este estado, alejado de todo terreno "humanizado" y que vive en las afueras de un orden racional, es que su forma de estar es meramente externa y cuantitativa. Los individuos se convierten en una multitud de particularidades que se resisten a todo tipo de determinación y medida, pues rehúyen de cualquier unidad objetiva, apareciendo así bajo la forma de la multitudo, la que tiene una vasta tradición al interior del pensamiento político moderno, habiendo sido despreciada por Hobbes y defendida por Spinoza ${ }^{40}$. En efecto, en esta línea Hegel se inclinará a favor de Hobbes, donde reluce la idea de pueblo, como unidad vinculante ${ }^{41}$, la que

\footnotetext{
${ }^{39}$ Hegel, G. W. F., Dissertatio Philosophica de Orbitis Planetarum (Las órbitas de los planetas), Bilbao, Servicio Editorial del País Vasco, 2009, p 162.

40 "Las dos polaridades, pueblo y multitud, tienen como padres putativos a Hobbes y Spinoza. Para Spinoza el concepto de multitud indica una pluralidad que persiste como tal en la escena pública, en la acción colectiva, lo que respecta a los quehaceres comunes - comunitarios- sin converger en Uno, sin desvanecerse en un movimiento centrípeto [...] Para Spinoza, la multitud es la base, el fundamento de las libertades civiles." Virno, Paolo, Gramática de la multitud, Madrid, Traficante de sueños, 2003, pp. 21-22.

"Hobbes detesta la multitud; arremete contra ella. En la existencia social y política de los muchos en tanto muchos, en la pluralidad que no converge en una unidad sintética, él percibe el máximo peligro para el «supremo imperio», esto es, para el monopolio de la decisión política del Estado." Ibid., p. 22.

${ }^{41}$ Esta influencia se encuentra marcadamente presente en sus años de juventud, donde representa la vida de la "figura concreta de la eticidad absoluta": "Puesto que aquí lo que importa, sobre todo, es la determinación de estas relaciones contenidas en ellas y, por tanto, resulta preciso resaltar el aspecto
} 
teóricamente se presenta en términos antitéticos a la idea de multitud $^{42}$. La referencia a ese estado se dirige a la forma propia de manifestarse, como una cantidad de individualidades, cada cual afirmada sobre sí misma y contra todo lo otro, sin una estructura que logre establecer una unidad, donde el quantum que significan aquellos átomos aislados, alcance un vínculo cualitativo, transformándose en la medida de aquella base sobre la que se desarrollará el mundo objetivo, como una realidad política.

Establecido como momento, el dominio de aquel quatum social que acontece en el estado de naturaleza, tiene su referente en el estado de guerra propio del pensamiento hobbesiano, donde la convivencia se presenta con la renombrada guerra de todos contra todos ${ }^{43}$. O tal vez sea justamente ésta, la guerra, la única categoría vinculante posible de este estado, la que hiere en su seno un tipo de relación, al punto de crear otras. Como es sabido, de este estado de guerra es de donde surge el pacto social en las teorías contractualistas. Y aunque tal posición es criticada por Hegel, sería justamente este estado el que aparece en las relaciones internacionales (donde se conservaría una relación natural) $\mathrm{y}$, de hecho, mantiene a tal nivel su importancia al interior del sistema que es justamente tal vinculo des-vinculante el que da el paso a la historia universal, momento final del espíritu objetivo (esto es, el universo del derecho), y exactamente anterior al espíritu absoluto ${ }^{44}$, cuestión que indica la persistencia de ese elemento natural que, pese al alto grado de espiritualización que se logra en el sistema, siempre se encontrará presente, desfondado las relaciones entre los hombres.

En suma, el estado de naturaleza que concibe Hegel, como momento de indiferencia cualitativa, donde se fortalecen los contenidos de cada particularidad, defendida a fuerza de potencia y poder natural, es semejante en características al presentado por el autor del Leviatán:

de la infinitud, presuponemos, pues, lo positivo; [o sea], que la absoluta totalidad ética no es sino un pueblo, lo que también se aclarará desde lo negativo, en sus momentos sucesivos.” G. W. F. Hegel, Sobre las maneras de tratar cientificamente el derecho natural, Madrid, Aguilar, 1979, p. 58.

42 En la Filosofia del derecho hará la drástica aclaración: "El estado es esencialmente una organización de tales miembros, que por sí constituyen círculos, y ningún momento debe mostrarse en él como una multitud inorgánica. Lo que se suele comprender como pueblo, la multitud de individuos, es por cierto un conjunto, pero sólo como una acumulación, como una masa carente de forma, cuya acción sería precisamente por ello elemental, irracional, desenfrenada y terrible.” G. W. F. Hegel, Principios de la filosofia del derecho, Op. Cit., p. 281.

En tanto que en la Enciclopedia realiza una distinción semejante, pero esta vez distinguiendo entre vulgus y populus: "El agrupamiento de personas privadas se suele llamar efectivamente y con frecuencia pueblo, pero como un conglomerado tal es vulgus, no populus; bajo este respecto el único fin del estado consiste en que un pueblo no llegue a EXISTIR como tal agrupamiento y no alcance poder ni actuación.” G. W. F. Hegel, Enciclopedia de las ciencias filosóficas, Op. Cit., p. 561.

43 Thomas Hobbes, Op. Cit., p. 104.

44 Tal aparición de la naturaleza al interior del sistema hegeliano, acontece peldaño a peldaño donde el espíritu debería campear a sus anchas. Con tal presencia se ve que aquello que es considerado en las teorías contractualistas como un momento anterior al orden civil, aparece en el filósofo alemán como un elemento fundamental dentro de la actividad del espíritu objetivo. 
Hobbes interpreta este estado en su verdadero sentido y no se entretiene en vacuas chácharas acerca de un estado natural bueno; el estado de naturaleza es, por el contrario, el estado animal, el estado de la propia voluntad no quebrantada $a^{45}$.

Sostener la bondad del estado natural es descabellado por unilateral; por razones recién dadas, el estado natural no es bueno, como tampoco malo, pues esto último caería en igual unilateralidad que su contrario: ni con Rousseau ni con Hobbes, se podría decir. Pero con éste último Hegel comparte las características que atribuye al estado referido, las cuales, representativamente se presentan en forma de desconfianza, de inseguridad, de competencia entre iguales, y conduce a la separación atomística de sus participantes, a una especie de enclaustramiento cerrado en cada uno de ellos, cuestión que ha sido repudiada desde la antigüedad y adquiere la célebre formulación en Aristóteles, donde aquel que se encuentra fuera de la dimensión política o social es "o un ser inferior o un ser superior al hombre"46. De modo que las caracterizaciones referidas al ámbito de la naturaleza, ya no como buena o mala en sí, escapan a cualquier determinación abstracta de lo que puede o no ser una individualidad o un momento natural, sacado de toda consideración humana (una historia natural, no humana, no es pensable, ratificaría Marx posteriormente ${ }^{47}$ ), contiene la eficacia de la negatividad en su interior y, por lo tanto, llama a su superación en la creación de un nuevo momento, el que devendrá, ya de suyo -en cuanto superación hecha por una autoconciencia- humano, como momento histórico.

Este paso, ya suficientemente caracterizado, del estado de naturaleza al civil, tiene también una formulación de mayor sistematización, en cuanto desarrollo de la Idea en los diversos aspectos que presenta la realidad, la cual se muestra en su verdad sólo con el desarrollo total y esto mediante una exposición filosófica de la misma. La explicación que hace Hegel del término naturaleza se presenta suficientemente esclarecedora para dar cuenta de ese desarrollo:

la palabra 'naturaleza' tiene un doble sentido: cuando hablamos de naturaleza del hombre queremos referirnos a su espiritualidad, a su condición de ser racional; pero cuando hablamos del 'estado de naturaleza' aludimos al estado contrario, en que el hombre obra con arreglo a su manera de ser natural. En este estado, el hombre se comporta dejándose llevar de sus apetitos, de sus instintos, etc., mientras que el estado de razón consiste en que el hombre se sepa dominar y sepa dominar sus impulsos naturales inmediatos ${ }^{48}$.

${ }^{45}$ G. W. F. Hegel, Lecciones sobre la historia de la filosofia, Op. Cit., p., 333.

${ }^{46}$ Aristóteles, Política, Madrid, Gredos, 1988, p. 50.

47 En los Manuscritos económico-filosóficos sostiene: "el total de lo que se llama historia del mundo no es más que la creación del hombre por el trabajo humano y el surgimiento de la naturaleza para el hombre, éste tiene, pues, la prueba evidente e irrefutable de su autocreación, de sus origenes." Karl Marx, Manuscritos económico-filosóficos, México, Fondo de Cultura Económica, 2005, pp. 147-148.

${ }^{48}$ G. W. F. Hegel, Lecciones sobre la historia de la filosofia, Op. Cit., p. 333. 
El doble sentido de la "naturaleza" descrito por Hegel debe ser leído como una exposición formal de cada uno de aquellos sentidos, siguiendo en la línea abstracta de exposición de la tradición iusnaturalista. En verdad, aquellos dos sentidos de la "naturaleza" no se encuentran separados, y menos entendiendo el primer sentido (naturaleza como racionalidad humana) sometiendo al segundo (como ser natural, en arreglo a sus afectos). Lo que acontece en el paso de uno a otro (de manera histórica, si seguimos la ficción que supone el estado de naturaleza) es que la naturaleza se convierte en campo de acción donde acontece lo racional, campo de acción, por lo demás, necesario para la realización concreta de esta racionalidad, lugar donde se produce su enajenación en lo otro de sí y desarrollo necesario para la realización de la Idea ${ }^{49}$.

Ahora se puede entender cómo el estado de naturaleza lejos de ser un momento separado del desarrollo del espíritu, forma parte de él, entendiéndolo como proceso dialéctico ${ }^{50}$ en que las contradicciones se presentan para ser superadas, y la necesidad de salir de semejante estado es visto en el sentido de que aquella salida transparenta su verdad en lo otro. Propiamente será la racionalidad la que le dará este sentido, cuando - gracias a la circularidad que supone el mismo proceso lógico- vuelva a aparecer, esta vez, en un momento superior del desarrollo del estado civil, en una formulación racional al interior de la eticidad, cuestión que acontece propiamente en la sociedad civil. Tal como sostiene Jean Francois Kervégan:

Más que un estado, el estado de naturaleza, movido por una dinámica contradictoria, es un proceso, al menos la ficción de un proceso: el de la constitución de un orden jurídico-político. El estado de naturaleza es lo otro del Estado, pero el transito del primero al segundo tiene lugar gracias a lo que en él prevalece y lo opone a sí mismo: la violencia, la negación del derecho ${ }^{51}$.

De esta manera, se subvierte el modo de entender el estado de naturaleza que es presentado como momento cercado por un límite con el estado civil,

49 Aunque sea como referencia, pero fundamental, es por esta realización de la idea en y como mundo $-\mathrm{y}$ por tanto ocupando su lugar dentro del sistema como la objetividad del espíritu- que el derecho pasa a formar parte del mundo ético y, para mayor realce, es en éste donde alcanza su momento más alto, en cuanto eticidad. Tal necesidad de esta realización la expone Hegel del siguiente modo en sus Lecciones sobre filosofia de la historia universal: "Los fines, los principios, etc., existen sólo en nuestro pensamiento, en nuestra intensión interna o también en los libros; pero aún no en la realidad. Lo que sólo es en sí, constituye una posibilidad, una potencia; pero no ha pasado todavía de la interioridad a la existencia. Es necesario un segundo momento para su realidad; y este momento es la actuación, la realización, cuyo principio es la voluntad, la actividad de los hombres en el mundo. Solo mediante esta actividad se realizan aquellos conceptos y aquellas determinaciones existentes en sí." Op. Cit., pp. 80-81.

50 Dicho esto en el sentido especifico hegeliano, cuando sostiene casi a modo de definición: "Llamo dialéctica al principio motor del concepto, que disuelve pero también produce las particularidades de lo universal." Hegel, Principios de la filosofía del derecho, Op. Cit., p. 51.

51 Jean Francois Kervégan, Hegel, Carl Schmitt. Lo politico: entre especulación y positividad, Madrid, Escolar y Mayo, 2007, pp. 211-212.

Araucaria. Revista Iberoamericana de Filosofía, Política y Humanidades, año 17, n ${ }^{\circ} 34$. Segundo semestre de 2015. Pp. 89-107. ISSN 1575-6823 e-ISSN 2340-2199 doi: 10.12795/araucaria.2015.i34.05 
moviéndose en la lógica de la cualidad, entendiéndose cada uno como lo otro de sí. Lo que se ha ganado es que con este proceso ya no se concibe el momento natural como algo dejado atrás sino, como el mismo Hegel asegura, la naturaleza "es la contradicción no resuelta" 52 , entendida ahora en su dimensión política. Y si bien Valls Plana asegura que tal "contradicción no tiene su desenlace en la naturaleza misma, pero sí en el espíritu" ${ }^{53}$, tal desenlace no hará sino perpetuarse en la tragedia que significa la naturaleza al interior del espíritu objetivo (esto es, en el universo del derecho y la política), como una extraña e incómoda permanencia que no se agotará de emerger. De hecho semejante permanencia es lo que posibilita el emerger de lo político, siendo el momento negativo que media y por tanto posibilita el aparecer del Estado, como realización de la idea.

\section{Conclusión}

Hegel rompe con la idea de que aquellos elementos del estado de naturaleza fueran categorías límites de la política, que amenazaban desde un afuera con derrumbar el orden interno. Por el contrario, la amenaza no es externa, sino que late permanentemente en el interior de lo político, cuestión que se ha presentado ocupando un lugar propio dentro de él. Las amenazas, por tanto, pierden su carácter de externas, y se convierten en momentos necesarios para el surgimiento del universal que, en la dimensión objetiva del espíritu, no es otra cosa que el Estado ${ }^{54}$. La movilidad e inquietud que provoca semejante caída subvierte el orden político mismo, dando origen a un nuevo modo de entender la política a partir de esta misma inquietud.

Sistemáticamente, esta forma de entender el desequilibrio político contiene otros elementos también desequilibrantes, y que se encuentran en la base de lo recién mencionado. Nos referimos a la intromisión de la naturaleza al interior del espíritu, la cual no hará sino soterrar elementos que una y otra vez socavaran la estructura política. La importancia de esto es fundamental, pues si la actividad de la voluntad es el eje estructural para todo el desarrollo de la Filosofia del derecho en $\mathrm{Hegel}^{55}$, esta actividad contiene $-\mathrm{y}$ por espiritual que pretenda llegar a ser, Hegel no puede librarse de ello- un fondo natural, que en

\footnotetext{
${ }_{52}^{52}$ G. W. F. Hegel, Enciclopedia de las ciencias filosóficas, Op. Cit., p. 306.

${ }^{53}$ Ibid., p. 306.

${ }^{54} \mathrm{Y}$ esto dicho en un sentido fuerte de la palabra. Cuando sostenemos que son "momentos necesarios", hablamos de una necesidad lógica, aquello que surge de la misma interioridad de las figuras del espíritu. Así, a cada una de las representaciones políticas que rompe con una concepción social existente, le corresponderá una formulación lógica que la fundamente y, específicamente, como corresponde a la sociedad civil, estos serán momentos de la lógica de la esencia, estructura lógica que atraviesa todo el desarrollo de la eticidad, hasta su realidad efectiva.

55 "El que una existencia sea existencia de la voluntad libre constituye el derecho." G. W. F. Hegel, Principios de la filosofia del derecho, Op. Cit., p. 49.
} 
todo momento actúa posibilitando la misma actividad volitiva.

La interiorización que se ha revisado en el universo político y la comunidad ética, ha revelado el fondo que imposibilita su realización, mediante las fallas que le son propias y, además, constitutivas. Con esto se ha querido manifestar que aquellos momentos que van paso a paso socavando la realización de la idea son necesarios no sólo para su desarrollo, sino que son necesarios, de igual modo, para su inicio. La sociedad moderna es la continuidad, al interior de la comunidad política, de este quiebre que se produce en la idea ética. El hundimiento que se da en cada una de sus capas revela sus posibilidades e imposibilidades, a la vez que indica aquello que será su legado, pues será en cada uno de los momentos de quiebre, tanto de la sociedad como del individuo, donde el pensamiento político post-hegeliano se internará, para proponerlos como puntos de partida y móvil de su teorización.

La modernidad procuró mantener a raya aquello que la abismaba, mediante un complejo sistema de mediaciones que contenía su fin inmanente y con él la posibilidad de sanar las heridas que, de persistir, hubieran imposibilitado cualquier tipo de organización comunitaria, orientado en el tipo de razón que la guiaba. Aquel fin es el Estado, cima y soberano de todo el orden político moderno. Sin embargo, éste (a diferencia de la polis griega, de la soberanía emanada de la ley eterna medieval, e incluso de la justificación procedente de la razón moderna) una vez que ha perdido su carácter soberano autónomo, revela la necesidad que tiene de cada uno de sus miembros para el desarrollo de su vida interior.

La concepción moderna del Estado tiene su base en esta figura política, pues es en el Estado donde "el individuo sólo tiene objetividad, verdad y ética" 56 , y, además, que es bajo esta figura que "la unión como tal es ella misma el fin y el contenido verdadero, y la determinación de los individuos es llevar una vida universal." ${ }^{57}$ Por ello, será justamente a partir de esta concepción desde donde se podrá extraer la persistencia moderna en el pensamiento político que le seguirá, pero contemplándola desde su revés, esto es: no desde su unión sustancial, ni del fin inmanente, sino de la ausencia de él. Es precisamente en el momento que esta cima del pensamiento político moderno, como es el pensamiento estatal, se derrumba, cuando aparecerá la herencia que se ha adquirido de aquel inmenso caudal que es la modernidad, como es su drama interno y su enfrentamiento cara a cara con la escisión al interior del sistema.

\footnotetext{
${ }^{56}$ Ibid., p. 228.

57 Ídem.
} 


\section{Referencias bibliográficas:}

Aristóteles, Política, Madrid, Gredos, 1988.

Benjamin, Walter, Hacía la crítica de la violencia [en Benjamin, Walter, Obras, libro II, vol. 1], Madrid, Abada, 2007.

Bobbio, Norberto, Hegel y el iusnaturalismo [en Diánoia, vol. 13, núm. 13, 1967], pp. 55-78.

Bobbio, Norberto y Michelangelo Bovero, Sociedad y Estado en la filosofía política moderna. El modelo iusnaturalista y el modelo hegelianomarxiano, México, Fondo de Cultura Económica, 1967.

Derrida, Jacques, Fuerza de ley. El «fundamento místico de la autoridad», Madrid, Tecnos, 2008.

Descartes, René, Meditaciones Metafísicas, Santiago de Chile, Editorial Universitaria, 1974.

Detienne, Marcel, Apolo con el cuchillo en la mano, Madrid, Akal, 2001.

Esposito, Roberto, Communitas. Origen y destino de la comunidad, Buenos Aires, Amorrortu, 2007.

Gernet, Louis, Droitet institutions en Grèce Antique, Paris, Flamarion, 2000 .

Grocio, Hugo, Del derecho de la guerra y de la paz, Madrid, Editorial Reus, 1925.

Hegel, Georg Wilhelm Friedrich, Ciencia de la lógica. I. La lógica objetiva, Madrid, Abada, 2011.

- Dissertatio Philosophica de Orbitis Planetarum (Las órbitas de los planetas), Bilbao, Servicio Editorial del País Vasco, 2009.

- Enciclopedia de las ciencias filosóficas, Madrid, Alianza Editorial, 2008.

- Lecciones sobre la historia de la filosofía, Tomo III, México, Fondo de Cultura Económica, 2005.

- Lecciones sobre la filosofía de la historia universal, Madrid, Alianza editorial, 1989.

- Principios de la filosofía del derecho, Buenos Aires, Editorial Sudamericana, 2004.

- Sobre las maneras de tratar cientificamente el derecho natural, Madrid, Aguilar, 1979.

Hobbes, Thomas, Leviatán, O la materia, forma y poder de una república eclesiástica y civil, México, Fondo de Cultura Económica, 2006.

Kervégan, Jean Francois, Hegel, Carl Schmitt. Lo político: entre especulación y positividad, Madrid, Escolar y Mayo, 2007.

Marx, Karl, Manuscritos económico-filosóficos, México, Fondo de Cultura Económica, 2005. 
Muñoz, Francisco, La Pax Romana [en Muñoz, Francisco y Beatriz Molina, eds.: Cosmovisiones de paz en el Mediterráneo antiguo y medieval, Granada, Editorial Universidad de Granada, Campus Universitario de Cartuja, 1998], pp. 191-228.

Mouffe, Chantal, En torno a lo político, Buenos Aires, Fondo de Cultura Económica, 2007.

Negri, Antonio, Spinoza subversivo, Madrid, Akal, 2000.

Rousseau, J. J., Discurso sobre el origen de la desigualdad entre los hombres, México, Porrúa, 2004.

Spinoza, Baruj, Tratado político, Madrid, Alianza Editorial, 2004.

Virno, Paolo, Gramática de la multitud, Madrid, Traficante de sueños, 2003.

Zarka, Yves Charles, Hobbes y el pensamiento politico moderno, Barcelona, Herder, 1997. 
